\title{
Structural Characteristic of the German-English Hybrids of the Information Security Sphere
}

\author{
Darya S. Poendaeva ${ }^{1, *}$, Juri $V$. Kobenko ${ }^{1}$, and Elena $S$. Riabova ${ }^{2}$ \\ ${ }^{1}$ National Research Tomsk Polytechnic University, 634050 Tomsk, Russia \\ ${ }^{2}$ Samara University, 443086 Samara, Russia
}

\begin{abstract}
The article describes the results of structural analysis of the German-English hybrid terms of the information security sphere. The obtained data testify to the serious impact of the English influence on German primarily in the peripheral sphere of the German language stock. The hybridity is stated as a result of aggregation of the literary German lexical system and language mixing owning to an invasive borrowing process.
\end{abstract}

\section{Introduction}

In the course of its evolution German to some extent has been subjected to the influence of more prestigious languages. Being the language of international communication English has had the greatest influence over German in last decades, which has led to invasive borrowing and mixing of the elements of the contacting languages in the system of the recipient-language. This phenomenon is known as hybridization or language mixing, which is the process of combining the elements of the recipient language with donor language citing [1]. Hybridization results from heterogeneity of a person's consciousness [2]. Every field of knowledge has its own definition of hybridity, what is common for all of them is that hybrids are created as a result of mixing objects with different properties and therefore acquires unique features and new functions. Particularly mixing of the languages of various arts can enrich the texts of a specific semiotic nature [3]. This also can be applied to different languages of all speech communities, which evolution and further existence depends upon this process. Hybridization is inseparable from the language nature as one of the word formation mechanisms [4]. Hybridization is mainly caused by extralinguistic factors, including interrelation between speech communities and local peculiarities of technological development. Hybridization is a complicated process as it can be applied to all levels of the language system. A great illustration of this statement is the Yiddish language, which initially was a mix of one of the German dialects, Slavic languages and Hebrew [5]. This example illustrates the leading role of extralinguistic factors as it clearly shows connection between structural changes in the systems of the languages and their relations. These kinds of processes are natural because borrowing is a condition for any language development [6]. Furthermore, the periods of active borrowing from a language

\footnotetext{
Corresponding author: poendaevads@ya.ru
} 
testify to the leading position of this language. However, it is the character of borrowing which defines an extent of the impact of the more prestigious language on the less prestigious and not the borrowing itself. Invasive borrowing occurs when a number of items, which were borrowed or are comprised of borrowed elements, prevails on a number of items formed by means of a recipient language [2]. To define a speech community status, a character of borrowing should be taken into consideration as borrowing is a part of any language development.

A language status is defined not only by the character of borrowing, but also by social, historical and cultural processes. A contact between two languages is always characterized by a non-equivalent mixing due to the degree of the donor language prestige among the recipient language speakers [4]. Diachronic description of the functional paradigms of literary languages at the different stages of their development is always based on the social processes and specific historical and cultural situation [7]. More explicitly hybridization can be seen at the lexicological level, where it is represented by terminological hybrids, which are new words, built by means of the elements, belonging to different languages [8]. Peripheral layers of the vocabulary, which contain the elements with weak or nonassimilated borrowed items, are most exposed to this process. A number of borrowed language elements in peripheral spheres may prevail on a number of autochthonous elements [6]. Information security is a relatively new field of knowledge, which as well as legal terminology uses terms of Internet and information technology spheres and thus can be considered peripheral.

Currently German-English terminological hybrids of the information security sphere are not fully examined. From this perspective studying functional characteristics of the terminology of the peripheral sphere appears to be required. The results would allow assessing more exactly, how considerable is the influence of the English language, being a donor, over the functional characteristics of the German language, being a recipient.

\section{Hybridity research in the German terminology of the information security sphere}

The database of terms was compiled from 12 documents and standards, published by Federal Office for Information Security of the Federal Republic of Germany [9] and official documents of the Organization for Economic Cooperation and Development (OECD) [10]. The terms were selected by means of continuous sampling method.

Survey of the selected text corpus revealed 104 terminological hybrids, including 9 comprised of one constituent (Cyber-Raum, Schadsoftware, Botnetz), 79 comprised of two constituents (Fault-Attacke, Bit-Folge, hardware-Plattformen) and 16 comprised of more than two constituents (Public-Key-Infrastruktur, Challenge-Response-Verfahren, relatedKey-Angriffe).

Structural analysis of the hybrids revealed the following.

Firstly, there are $74 \%$ of determinate items comprised of two constituents (FlashSpeicher, Push-Nachricht, OpenPGP-Zertifikat) (fig. 1) among all terminological hybrids of the German information security sphere. Items comprised of more than two constituents (IT-Grundschutz-Kataloge, MAC-Management-Nachricht) amount to $18 \%$ of the total number of the hybrids. Those comprised of one constituent (Botnetz, Trojaner) come to $8 \%$ of the total number of terms, including 4 items formed by means of prefixation (CyberRaum), 2 items formed by means of clipping a final part of the word (Schadsoftware), 2 items formed by means of composing stems of the words (Botnetz) and 1 item formed by adding an English suffix to a German stem (Trojaner). 
Fig. 1. Hybrids.

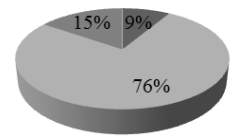

Secondly, $48 \%$ of the hybrids comprised of two or more constituents are terms which consist of simple constituents (Client-Server-Architektur, Unternehmens-Service), items comprised of only one compound constituent (SDN-Architektur, Full-MotionInhaltsfreigabe) represent $40 \%$ of the total (fig. 2); items comprised of two or more compound constituents (IP-Anlagenanschluss, IT-Grundschutz-Vorgehensweise) represent $12 \%$ of the total. Thirdly, one of the constituents of the compound terminological hybrids can be a numerical acronym (B2B-Bereich) or a clipped final part (E-Government-Dienst), initial constituent of which is an acronym and two final constituents are compounds (VoIPKommunikationslösung).

Simple constituents $₫$ One simple constituent $₫$ Two or more simple constituents

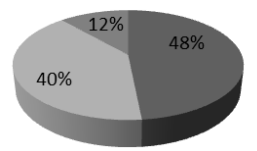

Fig. 2. Hybrids comprised of two and more constituents.

Compositional analysis of the hybrids showed, that all selected terms are determinates, $84 \%$ of which have a German determiner (DNS-Angriff) and $16 \%$ of which have an English determiner (AES-verschlüsselte E-Mail). Furthermore, 2\% of the com-pound terms have one hybrid determiner (IT-Sicherheitsmanager) (fig. 3).

In total, $52 \%$ of the English elements were borrowed to the German terminology of the information security sphere. Overall, 7 following hybrid patterns were discovered: $E+D$ (Mobile Dienste), D+E (Schadprogramm), E+E+D (IT-Governance-Beauftragten), E+D+D (IP-basierte Dienst), E+D+E (Bluetooth-Protokoll-Stack), D+E+D (Empfänger-E-MailAdresse) and $\mathrm{E}+\mathrm{E}+\mathrm{E}+\mathrm{D}$ (Internet Control Message Protokoll). The largest share is comprised of $\mathrm{E}+\mathrm{D}$ hybrids, which represent $70 \%$ of all hybrids. Almost equal shares of $11 \%$ and $10 \%$ are formed by $\mathrm{E}+\mathrm{E}+\mathrm{D}$ and $\mathrm{D}+\mathrm{E}$ hybrids. $\mathrm{E}+\mathrm{D}+\mathrm{D}$ и $\mathrm{E}+\mathrm{D}+\mathrm{E}$ hybrids make up $4 \%$ and $3 \%$. Finally, both $\mathrm{D}+\mathrm{E}+\mathrm{D}$ and $\mathrm{E}+\mathrm{E}+\mathrm{E}+\mathrm{D}$ hybrids amount to $1 \%$ of the total.

German-English Hybrid Patterns of the Information Technology Sphere:

1) $\mathrm{E}+\mathrm{D}$ (Mobile Dienste);

2) $\mathrm{D}+\mathrm{E}($ Schadprogramm);

3) $\mathrm{E}+\mathrm{E}+\mathrm{D}$ (IT-Governance-Beauftragten);

4) $\mathrm{E}+\mathrm{D}+\mathrm{D}$ (IP-basierte Dienst);

5) $\mathrm{E}+\mathrm{D}+\mathrm{E}$ (Bluetooth-Protokoll-Stack);

6) $\mathrm{D}+\mathrm{E}+\mathrm{D}$ (Empfänger-E-Mail-Adresse);

7) $\mathrm{E}+\mathrm{E}+\mathrm{E}+\mathrm{D}$ (Internet Control Message Protokoll).

- German determiner English determiner Hybrid determiner

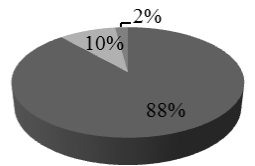

Fig. 3. Hybrids comprised of two and more constituents.

\section{Conclusion}


Language mixing can result in new sociolinguistic situations, causing a big number of research problems to appear. There is a real need for empirical research into these hybrid language situations. But it is plain that the emergence of hybrid trends and varie-ties raises all kinds of theoretical and pedagogical questions: They blur the long-standing distinctions between "first", "second" and "foreign" language. They make us reconsider the notion of "standard", especially when we find such hybrids being used confidently and fluently by groups of people who have education and influence in their own regional setting [11].

However hybridization is not just a process going beyond existing paradigms, but mainly a source of new standarts. This feature of hybrids was described by Stuart Hall and Homi K. Bhabha, who were the first to develop the theory of cultural hybridization: "The process of cultural hybridization gives rise to something different, something new and unrecongnisable, a new area of negotiation of meaning and representation" [12]. The literary works of V. Vertlib, who immigrated from the Soviet Union to Austria, can serve as an illustration of this statement. Vertlib created hybrid characters and features that combine elements of two different cultures and enrich the stylistic properties of his books [3].

The given statistics testifies to the special case of language mixing, which occurs in all levels of the system of a language. However, even examination of terminological hybrids is important in conveying an idea of the state of the language in the Ger-man speech community. Obtained results will help define a role played by English borrowings in the German language develop-ment. Nevertheless, structural change of the language system is only a superficial manifestation of the process, which has deeper roots. The obtained data can be used to solve strictly linguistic issues as well as implemented in the adjacent fields. Particularly, the results can be helpful to explore the rules of the speech communities functioning and development. The main conclusion which every researcher can draw when considering the data is that hybridization is inevitable and an indispensable condition of the further existence of any speech community.

\section{References}

1. Y. V. Kobenko, Linguistic situation in the Federal Republic of Germany: Americanization and Exoglossal tendencies (Tomsk Polytechnic University publishing house, Tomsk, 2014) [in Russian]

2. Y. M. Lotman, Rhetoric is the sense creating mechanism (History, Moscow, 1996). [in Russian]

3. V. G. Zusman, Russian Germanic Studies: Yearbook of the Russian Germanic Scholars Union. 10, 400 (2013)

4. Y. V. Kobenko, I. V. Sharapova Meditteranean Journal of Social Sciences MCSER Publishing, 6, 1 (2015)

5. K.A. Shishigin, Vestnik KemGUKI, 29, 111 (2014) [in Russian]

6. S. V. Grinyov-Grinevich, Terminology studies, manual for graduate students, 304, (2008) [in Russian]

7. Y.V. Kobenko, Language and the environment. Practice of classifying the data of the interdisciplinary research, 214, (2017). [in Russian]

8. A. V. Kravchenko, Cultural Interaction and Language Hybridization, Homo Communicans: a person in the intercultural communications, 80 (2012) [in Russian]

9. Documents published by Bundesamt für Sicherheit in der Informationstechnik (BSI) [Online version] URL: https://www.bsi.bund.de/

10. OECD Richtlinien für die Sicherheit von Informationssystemen und -Netzen: Organisation for Economic Co-operation and Development (OECD), Paris, (2003)

11. D. Crystal, English Today 15, 2 (1999) 
12. I. A. Ushanova, Russian Germanic Studies: Yearbook of the Russian Germanic Scholars Union 10, 400 (2013) [in Russian] 